\title{
The impact of biochemical control on the quality of life of patients with acromegaly
}

\author{
Emilia Solomon, Cristina Preda, Cristina Maria Gavrilescu, \\ Radu Gheorghe Solomon, Dumitru Brănișteanu
}

\begin{abstract}
Emilia Solomon - MD, PhD Student, „Grigore T. Popa” University of Medicine and Pharmacy, Iaşi, Romania, Department of Endocrinology, CF University Hospital, Iaşi, Romania

Cristina Preda - Associate Professor, MD, PhD, „Grigore T. Popa” University of Medicine and Pharmacy, Iaşi, Department of Endocrinology, „Sf. Spiridon” Hospital, Iaşi, Romania

Cristina Maria Gavrilescu - Lecturer, MD, PhD, „Grigore T. Popa” University of Medicine and Pharmacy, Iași, Vth Medical and Geriatrics - Gerontology Clinic, Iași

Radu Gheorghe Solomon - DDS, MDSI, PhD Student ISUD, University Lucian Blaga Sibiu

Dumitru Brănișteanu - Professor, $\mathrm{MD}, \mathrm{PhD}$, „Grigore T. Popa” University of Medicine and Pharmacy, Iași, Department of Endocrinology, „Sf. Spiridon” Hospital, Iaşi, Romania
\end{abstract}

\begin{abstract}
Purpose: Quality of life (Qol) is undoubtedly important for patient case management. The current goal of a treatment extends therefore beyond biochemical monitoring, including the physical, mental and social state of wellbeing. We aimed to correlate disease activity with the perception of Qol in acromegalic patients.
\end{abstract}

Methods: We performed a single center cross-sectional study on 26 patients: 9 men (34.6\%) and 17 women $(65.4 \%)$, with a mean age of $53 \pm 11.5$ years. Eleven patients $(42.3 \%)$ had a biochemically controlled disease, while 15 subjects $(57.7 \%)$ had an active disease.

Results: The mean total score of the quality of life was $60.9 \pm 12.6$ in women, ranging from 40 to 85 , while for men, the mean total score was of $64.04 \pm 14.78$, ranging from 42 to 85 $(p=0.575)$. There was no significant difference between the mean AcroQol scores of patients with controlled or active disease $(62.54 \pm 13.42$ vs $61.23 \pm 13.46, p=0.804)$. Patients younger than 60 had a significantly lower total score compared to older patients, $(58.36 \pm 14.17 \mathrm{vs}$ $64.26 \pm 12.44, p=0.047)$. Rural residents also scored lower than patients belonging to the urban region: $(58.18 \pm 11.21$ vs $67.19 \pm 14.39, p=0.048)$. Disease duration was negatively correlated with total score on AcroQol $(r=-0.253, p=0.045)$. We did not find significant correlations between GH and IGF1 levels and AcroQol ( $p=0,622$ and $p=0.844$, respectively).

Conclusions: We found no significant differences between males and females, as well as between patients with active and controlled disease regarding the Qol, but other factors like 

age or locality provenience may play some role for the perceived health status and quality of life in acromegalic patients

\section{KEYWORDS:}

\section{Quality of life; acromegaly; biochemical control}

\section{INTRODUCTION}

Acromegaly is a rare and chronic disease with an insidious evolution. The average time from the onset of the disease until the patient is diagnosed is about 5 to 10 years $(1,2)$. The pathognomonic signs are the enlargement of the extremities, hands, feet, tongue, nasal pyramid, frontal bossing and lower jaw protrusion. These features are associated with comorbidities: generalized musculoskeletal pain, osteoporosis and hip fractures, impaired heart function, sleep apnea and the decrease of physical force $(3,4)$. The top 5 most common comorbidities of acromegaly are: hypertension, diabetes, hypothyroidism, arthralgia / synovitis and sleep apnea $(5,6)$. These serious and at times irreversible changes have already occurred by the moment of diagnosis, predisposing the patient to affective disorders, commonly depression. There is also a tendency to sleep disorders, impaired attention, memory and social isolation (7,8). All these disease-related comorbidities can severely affect the quality of life of acromegaly patients and may lead to psychological sequelae (9-14).

The concept of quality of life evaluates the patient's perception on his/her physical, psychological and social wellness. The factors that minimize disease burden are: emotional and mental wellbeing, interpersonal relations, material wellbeing, a satisfying career that implies competence and a strong professional background, independence and social integration $(15,16)$. Psychosocial factors influencing patient's life are: pain, decreased range of motion, difficulty in usual daily activities, financial difficulties and cognitive deficits (17).

Currently, the most commonly used questionnaires of quality of life are: Short Form 36 (SF-36), Functional Assessment of Chronic Illness Therapy (FACIT), Nottingham Health Profile (NHP), EuroQol and to assess the impact cancer EORTC (European Organization for Research and Treatment of Cancer) QLQ .

AcroQol is a standardized questionnaire specifically designed for patients diagnosed with acromegaly and conceived in 2002 $(15,18,19)$.

The medical goal in acromegaly is to reduce mortality and morbidity by obtaining a longterm biochemical control. Studies reported conflicting results concerning biochemical control as a beneficial factor for the quality of life. The research conducted by Shih-CheHua et al on 52 acromegaly subjects aged between 20-76 years did not find any significant difference of total AcroQol score between patients with controlled or active disease, but they noted higher scores in patients treated with lanreotide compared to the group that did not receive this specific treatment (20). These findings are supported by other researchers $(12,18,21)$. Other studies found, however, a positive correlation between biochemical control and a better quality of life $(22,23)$.

The aim of this paper was to evaluate the biochemical control as a predictor factor for quality of life in patients with acromegaly. 
Bulletin of Integrative Psychiatry O New Series O December 2019 ○ Year XXV ONo. 4 (83)/73

\section{MATERIALS AND METHODS}

We conducted a cross-sectional, descriptive, analytical study on 26 acromegaly patients undergoing treatment at the Endocrinology Clinic of St Spiridon Hospital of Iași.

Thirty acromegaly patients were invited to complete the AcroQol questionnaire between January 2015 and January 2018. The exclusion criteria were major psychiatric disorders, stressful life events over the past year or comorbid cancers. Four patients refused, therefore a total of 26 remaining patients (9 men and 17 women) participated to this study.

The study was approved by the local ethical committee of Grigore T Popa University of Medicine and Pharmacy and was carried out according to the Declaration of Helsinki. All patients gave their informed written consent.

All patients admitted to this study had a diagnosis unequivocally established by specific tests and IRM for the pituitary gland. Biochemical control was based on GH levels $<0.4 \mu \mathrm{g} / \mathrm{L}$ at $2 \mathrm{~h}$ during the OGTT test with $75 \mathrm{~g}$ glucose and IGF-1 within 2 age and gender adjusted SD. Standard biochemical analysis and hormonal parameters (basal GH, IGF-1, PRL, LH, FSH, TSH, free T4, plasmatic cortisol at $8 \mathrm{am}$, testosterone for men and estradiol for women) were collected.

\section{Evaluation of the quality of life}

Quality of life was evaluated using a selfadministrated specific questionnaire for acromegaly. AcroQol (the Acromegaly Quality of life Questionnaire) assesses a perceived health status by evaluating the domains of physical status, appearance and personal relations. It comprises 22 questions with five possible responses ranging from 1 to 5 with a maximum score of 110 . Higher scores for the global and for all 3 dimensions indicate a better Qol.

\section{Data analysis}

The data obtained were analyzed in SPSS-18 using descriptive statistics including frequency, percentage, mean and standard deviation to describe the personaldemographic factors, quality of life and hormonal status. Pearson's correlation test was used to determine the relationship between the quality of life and duration of illness, GH and IGF-1. The one-way ANOVA and the independent t-test were used to determine the relationship between some of the personal-demographic factors and the quality of life.

\section{RESULTS}

Sociodemographic and clinical characteristics

The study group was composed of 9 men (34.6\%) and 17 women (65.4\%), with a mean age of $53 \pm 11.5$ years, higher in women than in men $(55.1 \pm 11.37$ vs $48.9 \pm 11.22$, $(\mathrm{p}=0.194)$. The study group had a predominance of rural females with an education ranging from 8 to 16 (mean of $12.22 \pm 3.03$ for men and $10.88 \pm 2.34$ for women, $\mathrm{p}=0.268$ ) and duration of known illness ranging between 1-45 years with a mean of $10.8 \pm 10.29$ (mean of $13.77 \pm 12.21$ years for men and $9.23 \pm 9.13$ years for women, $\mathrm{p}=0.345$ ).

Most patients $(23,88.46 \%)$ presented with a macroadenoma and 21 patients $(80.76 \%)$ were submitted to transsphenoidal surgery. Nine of these patients were further radiotreated. Mean GH and IGF-1 levels were $2.15 \pm 2.66 \mathrm{ng} / \mathrm{ml}$ and $281.38 \pm 182.5 \mathrm{ng} / \mathrm{ml}$ respectively.

\section{Quality of life}

The mean total score of the quality of life was of $60.9 \pm 12.6$ in women, (ranging between 40 


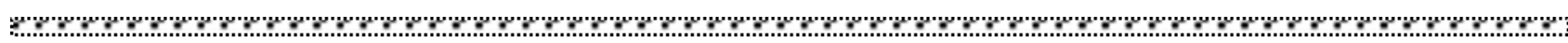

and 85), while in men, mean total score was of $64.04 \pm 14.78$, ranging between 42 and 85 $(\mathrm{p}=0.575)$. When patients younger than 60 years were compared with patients older than 60, a significant difference was noticed in the AcroQol $\quad(58.36 \pm 14.17$ vs $64.26 \pm 12.44$, $\mathrm{p}=0.047)$.

The physical dimension varied from 8 to 35 , with no significant differences between women and men $(21.59 \pm 6.4$ vs $22.22 \pm 6.91$, $\mathrm{p}=0.817$ ) or between patients younger and older than 60 years of age $(19.8 \pm 7.42$ vs $23.6 \pm 5.65, \mathrm{p}=0.216$ ).

The appearance dimension ranged from 10 to 31 , with no significant differences between women and men $(20.18 \pm 6.18$ vs $21.22 \pm 6.4$, $\mathrm{p}=0.689$ ) or between patients younger and older than 60 years of age $(19.2 \pm 6.18$ vs $21.7 \pm 6.17, \mathrm{p}=0.612$ ).

We also observed no significant differences regarding personal relationships between women and men ( 25.53 vs $26.44 ; \mathrm{p}=0.626$ ) and between younger and older patients (25.7 vs $25.94, \mathrm{p}=0.897$ ).

There was a significant negative correlation between the duration of disease and total AcroQol score $(r=-0.253, p=0.045)$, but no correlation between GH or IGF-1 levels and total AcroQol score $(\mathrm{r}=+0.101 ; \mathrm{p}=0.622$ and $\mathrm{r}=+0.041 ; \mathrm{p}=0.844$ for $\mathrm{GH}$ and IGF-1, respectively).

\section{Rural vs urban provenience}

Fifteen patients came from the countryside, while 11 lived in the city. Patients from the rural area had a lower AcroQol score (58.18 \pm 11.21 vs $67.19 \pm 14.39$ for the patients from the urban area, $\mathrm{p}=0.048$ ). They also scored poorer regarding personal relationships $(24.2$ \pm 4.2 vs $28.09 \pm 3.86, \mathrm{p}=0.024)$. There were no differences regarding the physical and appearance dimensions between the groups of countryside or city provenience $(20.07 \pm 5.15$ vs $24.18 \pm 7.49, \mathrm{p}=0.109$, and $20 \pm 6.57$ vs $21.27 \pm 5.75, \mathrm{p}=0.612$, respectively).

Relationship between illness perception and biochemical control

Eleven patients (42.3\%) had a biochemically controlled disease, while 15 subjects (57.69\%) had an active disease. Patients with controlled disease were not different from patients with active disease with respect to the total AcroQol score (62.54 \pm 13.42 vs $61.23 \pm$ 13.46, $(\mathrm{p}=0.804)$, physical dimension score, $(22.53 \pm 6.58$ vs $20.82 \pm 6.45, \quad(p=0.514)$, appearance score. $(20.73 \pm 6.26$ vs $20.40 \pm$ $6.28,(\mathrm{p}=0.896)$ or the personal relationships score $(26 \pm 4.64$ vs $25.65 \pm 4.34,(p=0.841)$.

\section{The effect of radiotherapy on quality of life}

The AcroQol global score of patients with acromegaly and submitted to radiotherapy did not differ from non-irradiated patients $(62.52$ \pm 14.77 vs $61.71 \pm 12.73, \mathrm{p}=0.885)$. No difference was observed between irradiated and non-irradiated patients also regarding any of the three domains of AcroQol: physical domain (23.44 \pm 7.37 vs $20.94 \pm 5.96$, $\mathrm{p}=0.357)$, appearance $(19.22 \pm 5.95$ vs 21.24 $\pm 6.31, \mathrm{p}=0.438)$ and personal relationships $(26.22 \pm 5.04$ vs $25.65 \pm 4.23$, $\mathrm{p}=0.760)$.

\section{DISCUSSION}

Medical intervention should not focus only on prolonging life span, but also on fulfilling the desire of patients to have a pleasant life, based on personal and social wellbeing.

Quality of life is a multidimensional complex that covers the physical wellbeing (the perception of the individual of his/her health), psychological aspects (subjective perception regarding the cognitive and affective state) and social aspects (aiming interpersonal relationships). Asthenia accompanied by lack of interest for the environment and usual 
activities and pain, especially related to osteoarticular complications, are common in acromegaly and can generate a high degree of suffering and disability, altering the quality of life (24-27).

In our transversal study, we found no significant differences between genders regarding the quality of life. Literature data is discordant. Whereas certain authors did not find, similar to us, any gender-related differences (12), others found a lower Qol in women $(18,28)$. An interesting study using 3D facial analysis stereophotography showed that men are more at risk to develop dysmorphic facial features, with more pronounced nose width, length and depth, face length, width, gonion-gnathion distances and nasofrontal and columella-labial angles (29). Despite these morphological findings, Qol seems to be significantly hampered to at least the same extent in both genders, if not even more in women. This discordance is caused by the fact that Qol is a subjective, self-perceived state of health, not necessarily overlapping the severity of clinical modifications. Body shape dissatisfaction is therefore more related to a lower Qol than the amplitude of dysmorphism. Women seem therefore more sensitive to body changes, especially facial features, than men. The Qol of acromegalic women could also be influenced by frequent sexual dysfunction concerning desire, arousal and satisfaction (30).

Our study showed that rural provenience was associated with lower quality of life. Patients from the countryside achieved a lower global score and also scored poorer at personal relationships, while no significance was reached regarding physical wellbeing and appearance satisfaction. These findings probably highlight the importance of a good neighborhood, the availability of facilities and the housing comfort and safety(31,32). Rural residents may also have issues accessing quality healthcare due to socioeconomic disadvantage or distance $(33,34)$.

Our younger patients dealing with acromegaly have lower quality of life. This finding is in accordance with other studies and it applies also to other dysmorphic conditions(16). Subjects under 60 years old are more interested to be accepted by the society, therefore body dysmorphism augments their adaptation stress, especially when the disease has a disfiguring nature leading to anthropometric changes and body image disturbance $(8,35)$. Older patients have different issues, such as understanding their disease and risk of acromegaly-related comorbidities, thereby accepting their disease condition with diminished stress (36).

Half of the patients with acromegaly have anxiety and insomnia related to the acceptance of the illness. The psychological component seems therefore to play an important for patient Qol (7). Coping strategies, such as problem- solving and positive thinking actions, may diminish psychological distress such as anxiety and depression also in acromegalic patients. Cognitive behavioral therapy such as the 'Think healthy' technique were promising also in acromegalic patients (37).

We did not find any correlation between the levels of GH or IGF-1 and the quality of life of our acromegalic patients. Our data are in line with those obtained by other authors $(21,38,39)$. In contrast, other authors suggested that patients with active acromegaly or higher IGF1 bioactivity may achieve lower AcroQoL scores when compared with patients having controlled disease $(23,40)$. 
(1) Although there are still inconsistencies concerning the benefit of a biochemical control on the Qol of acromegalic patients, the normalization of $\mathrm{GH}$ and IGF-1 levels may have an indirect effect by preventing comorbidities. Musculoskeletal pain is the most frequent complaint affecting up to $90 \%$ of patients dealing with acromegaly and is negatively correlated with the Qol (14). The therapy of acromegaly diminishes this complication, thereby possibly improving the Qol. Acromegalic patients treated with somatostatin receptor agonists scored higher at the AcroQol test than non-treated patients

\section{LIMITATIONS AND STRENGTHS}

The major limitation of our study is the small number of enrolled acromegalic subjects. Acromegaly is a rare disease, but our single center cross-sectional study could be improved by enlarging it to a multicenter study.

Our study's strength is the design originality, combining the assessment of gender, age, settlement and duration of the disease and its biochemical control on all the components of Qol. (20).

\section{CONCLUSIONS}

Quality of life is important as a tool for investigating the satisfaction of patients and the therapeutic impact on their wellbeing. Our study demonstrates that achieving a biochemical control does not entirely overlap an improvement of the quality of life of acromegalic patients. Other conditions, such as patient's age or settlement may have an important influence on the quality of life of acromegalic patients. Qol evaluation helps the clinician and the psychologist to offer adequate support for the patient. A holistic approach, rather than only achieving a biochemical control is the key for a better quality of life of acromegalic patients.

\section{ACKNOWLEDGE AND DISCLOSURE}

The authors declare that they have no conflicts of interest that would prejudice the impartiality of this scientific work.

\section{REFERENCES}

1 Melmed S, Casanueva FF, Klibanski A, Bronstein MD, Chanson P, et al. (2013) A consensus on the diagnosis and treatment of acromegaly complications, Pituitary. doi:10.1007/s11102-012-0420-x.

2 Siegel S, Streetz-Van.Der Werf C, Schott JS, Nolte K, Karges W, et al. (2013) Diagnostic delay is associated with psychosocial impairment in acromegaly, Pituitary..

3 Ben-Sholmo A, Sheppard MC, Stephens JM, Pulgar S, Melmed S. (2011) Clinical, quality of life, and economic value of acromegaly disease control, Pituitary.

4 Compostela AS, Giustina A, Chanson P, Kleinberg D, Bronstein MD, et al. (2014) Expert consensus document: A consensus on the medical treatment of acromegaly, Nat. Rev. Endocrinol.. doi:10.1038/nrendo.2014.21.

5 Arosio M, Reimondo G, Malchiodi E, Berchialla P, Borraccino A, et al. (2012) Predictors of morbidity and mortality in acromegaly: An Italian survey, Eur. J. Endocrinol. doi:10.1530/EJE-12-0084.

6 Placzek H, Xu Y, Mu Y, Begelman SM, Fisher M. (2016) Clinical and Economic Burden of Commercially Insured Patients with Acromegaly in the United States: A Retrospective Analysis, J. Manag. Care Spec. Pharm. doi:10.18553/jmcp.2015.21.12.1106.

7 Szczë̈niak D, Jawiarczyk-Przybyłowska A, Rymaszewska J. (2015) The quality of life and psychological, social and cognitive functioning of patients with acromegaly, Adv. Clin. Exp. Med.. doi:10.17219/acem/38156.

8 Conaglen HM, de Jong D, Crawford V, Elston MS, Conaglen JV. (2015) Body Image Disturbance in Acromegaly Patients Compared to Nonfunctioning Pituitary Adenoma Patients and Controls, Int. J. Endocrinol. doi:10.1155/2015/624872. 
r.n. 9 Anagnostis P, Efstathiadou ZA, Charizopoulou M, Selalmatzidou D, Karathanasi E, et al. (2014) Psychological profile and quality of life in patients with acromegaly in Greece. Is there any difference with other chronic diseases? Endocrine. doi:10.1007/s12020-014-0166-5.

10 Colao A, Pivonello R, Scarpa R, Vallone G, Ruosi C,et al. (2005) The acromegalic arthropathy., J. Endocrinol. Invest.

11 Dantas RAE, Passos KE, Porto LB, Zakir JCO, Reis MC, et al. (2013) Physical activities in daily life and functional capacity compared to disease activity control in acromegalic patients: impact in self-reported quality of life, Arq. Bras. Endocrinol. Metabol. doi:10.1590/S0004-27302013000700009.

12 Geraedts VJ, Andela CD, Stalla GK, Pereira AM, van Furth WR., et al. (2017) Predictors of quality of life in acromegaly: No consensus on biochemical parameters, Front. Endocrinol. (Lausanne).. doi:10.3389/fendo.2017.00040.

13 Miller A, Doll H, David J, Wass J. (2008) Impact of musculoskeletal disease on quality of life in long-standing acromegaly, Eur. J. Endocrinol. doi:10.1530/EJE-07-0838.

14 Wassenaar MJE, Biermasz NR, Kloppenburg M, va. der Klaauw AA, Tiemensma J, et al. (2010) Clinical osteoarthritis predicts physical and psychological QoL in acromegaly patients, Growth Horm. IGF Res. doi:10.1016/j.ghir.2010.02.003.

15 Crespo I, Santos A, Resmini E, Valassi E, Martínez-Mombla'n MA, et al. (2014) Improving quality of life in patients with pituitary tumors, US Endocrinol.

16 Gambin G, Molzahn A, Fuhrmann AC, Morais EP, Paskulin LM. (2015) Quality of life of older adults in rural southern Brazil, Rural Remote Health.

17 Muldoon MF, Barger SD, Flory JD, Manuck SB. (1998) What are quality of life measurements measuring?, BMJ. doi:10.1136/bmj.316.7130.542.

18 Webb SM, Badia X. (2016).Quality of Life in Acromegaly, Neuroendocrinology. doi:10.1159/000375451.

19 Webb SM, Badia X, Surinach NL, Astorga R, Benito P, et al. (2006) Validity and clinical applicability of the acromegaly quality of life questionnaire, AcroQoL: A 6-month prospective study, Eur. J. Endocrinol. doi:10.1530/eje.1.02214.

20 Hua SC, Yan YH, Chang TC. (2006) Associations of remission status and lanreotide treatment with quality of life in patients with treated acromegaly, Eur. J. Endocrinol. doi:10.1530/eje.1.02292.

21 T'Sjoen G, Bex M, Maiter D, Velkeniers B, Abs R. (2007) Health-related quality of life in acromegalic subjects: data from AcroBel, the Belgian Registry on acromegaly, Eur. J. Endocrinol. 157 411-417. doi:10.1530/eje-07-0356.

22 Paisley AN, Rowles SV, Roberts ME, Webb SM, Badia X, et al. Trainer. (2007) Treatment of acromegaly improves quality of life, measured by AcroQol, Clin. Endocrinol. (Oxf).. doi:10.1111/j.1365-2265.2007.02891.x.

23 Trepp R, Everts R, Stettler C, Fischli S, Allemann S, et al. (2005) Assessment of quality of life in patients with uncontrolled vs. controlled acromegaly using the Acromegaly Quality of Life Questionnaire (AcroQoL).(Erratum appears in Clin Endocrinol (Oxf). 2005 Aug;63(2):238), Clin. Endocrinol (Oxf).

24 Kauppinen-Mäkelin R, Sane T, Sintonen H, Markkanen H, Välimäki MJ, et al. (2006) Quality of life in treated patients with acromegaly, J. Clin. Endocrinol. Metab. doi:10.1210/jc.2006-0676.

25 Matta MP, Couture E, Cazals L, Vezzosi D, Bennet A,et al. (2008) Impaired quality of life of patients with acromegaly: Control of GH/IGF-I excess improves psychological subscale appearance, Eur. J. Endocrinol. $158305-$ 310. doi:10.1530/EJE-07-0697.

26 Psaras T, Honegger J, Gallwitz B, Milian M. (2011) Are there gender-specific differences concerning quality of life in treated acromegalic patients?, Exp. Clin. Endocrinol. Diabetes. doi:10.1055/s-0030-1267912.

27 Vandeva V, Yaneva M, Natchev E, Elenkova A, Kalinov K, et al. (2015) Disease control and treatment modalities have impact on quality of life in acromegaly evaluated by Acromegaly Quality of Life (AcroQoL) Questionnaire, Endocrine. doi:10.1007/s12020-014-0521-6.

28 Garduño-Pérez AA, Zamarripa-Escobedo R, Vergara-López A, Guillén-González MA, Escudero-Licona I. (2011) Artículo original Análisis de la calidad de vida en pacientes con acromegalia en el Centro Médico Nacional 20 de Noviembre, ISSSTE, 19 97-101.

29 Guo X, Meng T, Huang J, Wang X, Lian W, et al. (2018) 3D Facial Analysis in Acromegaly: Gender-Specific Features and Clinical Correlations, Front. Endocrinol. (Lausanne).. doi:10.3389/fendo.2018.00722.

30 Celik O, Kadioglu P. Quality of life in female patients with acromegaly. (2013) J. Endocrinol. Invest. doi: $10.3275 / 8761$.

31 Gobbens RJJ, Remmen R. (2019) The effects of sociodemographic factors on quality of life among people aged 50 years or older are not unequivocal: Comparing SF-12, WHOQOL-BREF, and WHOQOL-OLD, Clin. Interv. Aging. doi:10.2147/CIA.S189560. 

32 Puts MTE, Shekary N, Widdershoven G, Heldens J, Lips P, et al. (2007) What does quality of life mean to older frail and non-frail community-dwelling adults in the Netherlands?, Qual. Life Res. doi:10.1007/s11136-006-9121-0.

33 Mu R. (2014) Regional disparities in self-reported health: Evidence from Chinese older adults, Heal. Econ. (United Kingdom). doi:10.1002/hec.2929.

34 Zhou Z, Gao J, Lai S, Chen G. (2018) Urban-rural difference in the associations between living arrangements and the health-related quality of life (HRQOL) of the elderly in China-Evidence from Shaanxi province, PLoS One. doi:10.1371/journal.pone.0204118.

35 Dimopoulou C, Sievers C, Wittchen HU, Pieper L, Klotsche J, et al. (2010) Adverse anthropometric risk profile in biochemically controlled acromegalic patients: Comparison with an age- and gender-matched primary care population, Pituitary. doi:http://dx.doi.org/10.1007/s11102-010-0218-7.

36 Jackson Y, Flood E, Rhoten S, Janssen EM, Lundie M. (2019) AcroVoice: eliciting the patients' perspective on acromegaly disease activity, Pituitary. doi:10.1007/s11102-018-00933-9.

37 Kunzler LS, Naves LA, Casulari LA. (2018) Cognitive-behavioral therapy improves the quality of life of patients with acromegaly, Pituitary. 21 323-333. doi:10.1007/s11102-018-0887-1.

38 Postma M, Netea-Maier RT, van den Berg GP. (2012) Quality of life is impaired in association with the need for prolonged postoperative therapy by somatostatin analogs in patients with acromegaly, Eur. J. Endocrinol.

39 Rowles SV, Prieto L, Badia X, Shalet SM, Webb SM, Trainer PJ. (2005) Quality of life (QOL) in patients with acromegaly is severely impaired: Use of a novel measure of QOL: Acromegaly Quality of Life Questionnaire, J. Clin. Endocrinol. Metab.

40 Varewijck AJ, van der Lely AJ, Neggers SJ, Lamberts SW, Hofland LJ, et al. (2014) In active acromegaly, IGF1 bioactivity is related to soluble Klotho levels and quality of life, Endocr. Connect. doi:10.1530/ec-14-0028.

\section{Correspondence:}

Cristina Preda,

MD, PhD, professor, "Grigore T. Popa” University of Medicine and Pharmacy, No 16, Universităţii Street, Iaşi, 700115, Romania, cpreda1@yahoo.com

Submission: 05 sep2019

Acceptance: 29 nov2019 